\title{
Intoxicación por rodenticida anticoagulante de acción prolongada ¿Publicación duplicada? (2)
}

\section{Long-acting anticoagulant rodenticide poisoning ¿Duplicate publication? (2)}

\author{
Julio Pedro Ramírez Erazo' \\ jramireze@unmsm.edu.pe
}

Sr. editor:

1. Ante todo, debo saludarlo atentamente, no antes también manifestarle que he sido y soy respetuoso de las leyes, reglamentos y normas de vida en el ejercicio de mi profesión docente y administrativa.

2. Estando al mando administrativo y académico de la sala Santo Toribio del Hospital Dos de Mayo de Lima, hasta el 2020, en el 2019 se produjo el internamiento del paciente del caso reportado en mi sector, elaborándose la historia clínica para este reporte a cargo de la Srta. alumna Diana Gonzales como parte de su actividad académica en el curso de medicina interna, bajo mi conducción docente. El caso fue discutido en el servicio con otros alumnos de la universidad con la supervisión del Dr. Víctor Mechan Méndez, profesor principal del capítulo de hematología, durante el curso de medicina interna anual del 2019.

3. En mi calidad de jefe docente para alumnos, internos y residentes de la UNMSM di instrucciones para que se preparara y se publicara este caso clínico como reporte dada la trascendencia, la minuciosidad y el acopio bibliográfico realizado con esfuerzo, siendo el artículo enviado en noviembre del 2019 a la Revista Peruana de Salud Pública y Medicina Experimental (RPSPME), no siendo aceptado por no concordar con la línea editorial de la revista. Por aquel entonces, le

I Médico internista. Hospital Dos de Mayo de Lima. Profesor asociado, Facultad de Medicina, Universidad Nacional Mayor de San Marcos, Lima, Perú.
Ramírez Erazo JP. Intoxicación por rodenticida anticoagulante de acción prolongada ¿Publicación duplicada? (2). Rev Soc Peru Med Interna. 2021;34(3):I24. https://doi.org/10.36393/spmi.v34i3.615

fue comunicado a la médica destacada al servicio, Dra. Marisa Riveros Anglas, y procedente del Centro de Salud de Huachipa, de que el caso había sido enviado a la revista del RPSPME para su publicación.

4. Desatada la pandemia en el año 2020, fue difícil insertary publicar el artículo en mención en otras revistas por razones obvias, había prioridad por publicaciones relacionadas con artículos sobre COVID-19.

En el 2021, lo enviamos a la prestigiosa revista que usted dirige, siendo aceptada y publicada. 1

5. La Dra. Marisa Riveros Anglas me comunicó la intención de publicar otro artículo relacionado con el mismo caso, en calidad de coautor corresponsal, por lo cual le reiteré que ya habíamos enviado el artículo a publicar, no aceptando cortésmente su propuesta.

6. No obstante, siguió insistiendo hasta los días 14 y 15 de junio del presente 2021, declinando cortésmente a su invitación para una publicación futura. No le proporcioné mi firma para la coautoría ni le facilité mi número de ORCID.2

Lima, 4 de Julio 2021

\section{REFERENCIAS BIBLIOGRÁFICAS}

I. Mechan-MéndezV, Ramírez-Erazo JP, Gonzales-Rafael D. Intoxicación humana intencional por rodenticida anticoagulante de acción prolongada. Rev Soc Peru Med Interna. 202I;34(2): 65-68. https:// doi.org/ / 0.36393/spmi.v34i2.598

2. Riveros-Anglas M, Ramirez-Erazo J, Loayza-Urcia N, AlarcónVílchez R, Santos-Quezada A. Intoxicación por rodenticidas (raticidas) con superwarfarinas efecto anticoagulante altamente prolongado.Diagnóstico (Lima). 202 I;60(2): I04- I I2.DOI: I0.33734/ diagnostico.v60i2.288 